\title{
Supraventricular Tachycardia, CTCAE
}

National Cancer Institute

\section{Source}

National Cancer Institute. Supraventricular Tachycardia, CT CAE. NCI Thesaurus. Code C54945.

A disorder characterized by a dysrhythmia with a heart rate greater than 100 beats per minute that originates above the ventricles. 